\title{
Centralised versus decentralised manufacturing and the delivery of healthcare products: A United Kingdom exemplar
}

\author{
RICHARD P. HARRISON ${ }^{1,2}$, QASIM A. RAFIQ ${ }^{3} \&$ NICHOLAS MEDCALF $^{1}$ \\ ${ }^{1}$ Centre for Biological Engineering, Holywell Park, Loughborough University, Loughborough, United Kingdom, \\ ${ }^{2}$ Wolfson Centre for Stem Cells, Tissue Engineering and Modelling (STEM), School of Medicine, Nottingham, United \\ Kingdom, and ${ }^{3}$ Department of Biochemical Engineering, Faculty of Engineering Science, University College London, \\ Gower Street, London, United Kingdom
}

\begin{abstract}
Background. The cell and gene therapy (CGT) field is at a critical juncture. Clinical successes have underpinned the requirement for developing manufacturing capacity suited to patient-specific therapies that can satisfy the eventual demand post-launch. Decentralised or 'redistributed' manufacturing divides manufacturing capacity across geographic regions, promising local, responsive manufacturing, customised to the end user, and is an attractive solution to overcome challenges facing the CGT manufacturing chain. Methods. A study was undertaken building on previous, so far unpublished, semistructured interviews with key opinion leaders in advanced therapy research, manufacturing and clinical practice. The qualitative findings were applied to construct a cost of goods model that permitted the cost impact of regional siting to be combined with variable and fixed costs of manufacture of a mesenchymal stromal cell product. Results. Using the United Kingdom as an exemplar, cost disparities between regions were examined. Per patient dose costs of $\sim £ 1,800$ per 75,000,000 cells were observed. Financial savings from situating the facility outside of London allow 25-41 additional staff or 24-35 extra manufacturing vessels to be employed. Decentralised quality control to mitigate site-to-site variation was examined. Partial decentralisation of quality control was observed to be financially possible and an attractive option for facilitating release 'at risk'. Discussion. There are important challenges that obstruct the easy adoption of decentralised manufacturing that have the potential to undermine the market success of otherwise promising products. By using the United Kingdom as an exemplar, the modelled data provide a framework to inform similar regional policy considerations across other global territories.
\end{abstract}

Key Words: advanced manufacturing technology, cell and gene therapy, cost of goods, decentralised manufacturing, organisational change, quality control

\section{Introduction}

Disruptive changes in advanced therapy manufacturing

Centralised manufacturing has been the dominant model for large-scale production of goods since the Industrial Revolution [1]. Centralising workers and materials to benefit from economies of scale was pioneered by the early 'Fordist' factories and allowed costs to be contained [2]. Increasing attention is now being paid to the potential for a network of decentralised production facilities to provide cell and gene therapy (CGT) manufacturing capacity [3]. In common with other regions of the developed world, the United
Kingdom is under pressure to increase the efficiency of manufacturing, to create valuable professionallevel jobs across all regions [4] and to reduce carbon footprint associated with the shipping of thermally controlled goods over long distances [5].

Decentralised manufacturing (DCM) divides manufacturing capacity across geographic regions and thus represents a radical departure for most existing healthcare supply systems. To achieve this, significant changes must be made to the traditional flow of materials and information and the aggregation of manufacturing processes [2]. Both centralised and DCM paradigms can be conceptualised as 'process

Correspondence: Richard P. Harrison, PhD, Centre for Biological Engineering, Holywell Park, Loughborough University, Loughborough, LE11 3TU, United Kingdom. E-mail: r.p.harrison@1boro.ac.uk 
modules' and the options for each can then be examined separately (Figure 1).

Despite the challenges in terms of batch reproducibility that decentralisation of manufacturing facilities may introduce [1], it remains an attractive choice in principle for manufacturing certain CGTs. This is primarily due to the perishability of these products and the limited options for storage and shipping making long-distance transit undesirable [6]. Additionally, products that require a late-stage customisation or 'mass customisation', such as a bio-printed threedimensional (3D) scaffold, are particularly suited to being manufactured close to a clinical setting [7].

A decentralised network allows manufacturing to be located proximal to treatment centres and this dictates to some degree the geographical location. The social function of the DCM suite and associated treatment centres demands that they should be situated in the heart of the society that they serve. Similarly, accessibility is paramount and the centres must be within reach of their users. Using an out-of-town brownfield site or suburban estate, it may be cheaper to establish a traditional manufacturing centre, but these do not necessarily suit delivery of products to users. Defining the catchment areas for treatment is a first step in deciding the location [8], however, there are a multitude of other regional pressures and business operational concerns that affect the implementation of a successful DCM network.

\section{The decentralised manufacturing 'Smart Factory'}

Production of CGTs has different requirements from pharmaceuticals or biologics. Attempts to use existing manufacturing strategies have yielded poor outcomes $[9,10]$. With the rapid advancements in the technical capability for CGT manufacturing systems, the promise of large-scale, small-footprint manufacturing is becoming a reality through, for example, autonomous biological factories. The purpose of such a factory is to operate to a pre-defined set of process instructions via installed firmware programs to reduce operator discretion. It is this reduction of operator discretion that would reduce variability across a DCM network and is thus a critical requirement for success. The interconnection of industrial environments has been an area of intense systems engineering research. The exact terminology varies between stakeholders and includes "Smart Factories" (IBM), "Industrial Internet" (GE), "The Factory of the Future" (Airbus) and "Industrie 4.0" (Germany) $[11,12]$. The key themes include next-generation manufacturing, use of big data, automation, logistics and supply chain management, smart networks and communication. Together these describe an interconnected manufacturing value chain with equipment configu- rations able to respond autonomously to demands and pressures with minimal operator interaction.

Although there are promising candidate 'smart factory' solutions both commercially available and under development [13], there is currently no truly autonomous solution able to claim successes in all of these defining areas of a 'smart factory'. Of the commercially available systems [13], two platforms are available that, with further modification, could begin to fulfil the requirements or an autonomous 'smart micro-factory' suitable for DCM. These two exemplar platforms are described in Figure 2. Both provide semi-autonomous culture of cell products, but differ in their approach with one using existing culture technology (flasks) and mimicking human processes while the modular stirred tank reactor scales the process up to facilitate greater culture potential in a smaller footprint. This scale-up approach is undoubtedly more cost effective [14] and has the additional benefit of being simpler than flask-based approaches to enhance when developments in sensory and manipulation technology justify retrofitting such technology.

\section{A UK case study of progress toward DCM}

With an active and capable manufacturing workforce, an actively engaged single-payer healthcare sector and a strong commitment from central government to place advanced therapy manufacturing at the forefront of investment policy, the United Kingdom remains an attractive choice for a hypothetical DCM environment. The recent vote to leave the European Union has generated intense dialogue around the topic of the relationship between the United Kingdom and its markets overseas and how the United Kingdom may capitalise on arising opportunities. This has taken place mainly between government and other stakeholders and provides useful perspectives on how investment, manufacturing, technologies and healthcare pathways can be deployed to encourage the commercial translation of CGTs. This provides a valuable context for examining hypothetical DCM scenarios.

A number of key points recommended in the recent Advanced Therapies Manufacturing Action Plan from the UK Medicines Manufacturing Industry Partnership [15] resonate strongly with DCM. Key recommendations from the report include a comprehensive strategy to secure inward investment, generation and retention of both manufacturing capability and a talented workforce within the United Kingdom and finally using novel social and regulatory approaches to help grow businesses within the United Kingdom.

With the addition of the Cell and Gene Therapy Catapult Manufacturing Facility to the UK infrastructure and the assignment of funding to three new Advanced Therapy Treatment Centres (see below), the 


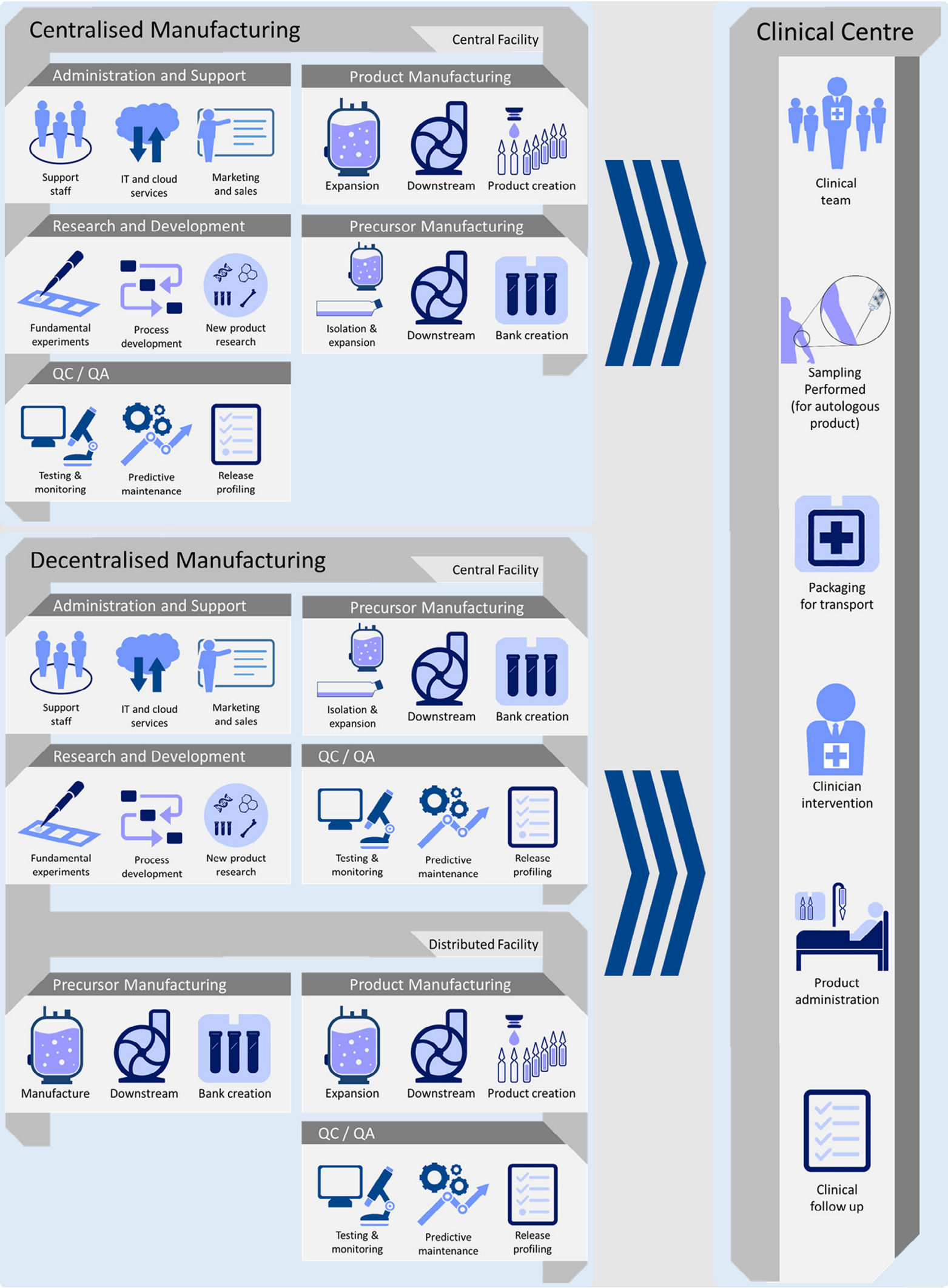

Figure 1. An overview of potential operational paradigms for DCM compared with centralised manufacturing. The CGT product life cycle can be broken down into multiple process modules, which are then assigned to a geographical region. In a centralised model, these are primarily carried out at the centralised facility, whereas at a decentralised facility, these steps are distributed throughout the geographical network. The DCM suite may be located within the clinical centre or elsewhere but will need to retain quality control and quality assurance $(\mathrm{QC}) /(\mathrm{QA})$ abilities to perform testing on and between processes (e.g., line clearance). 

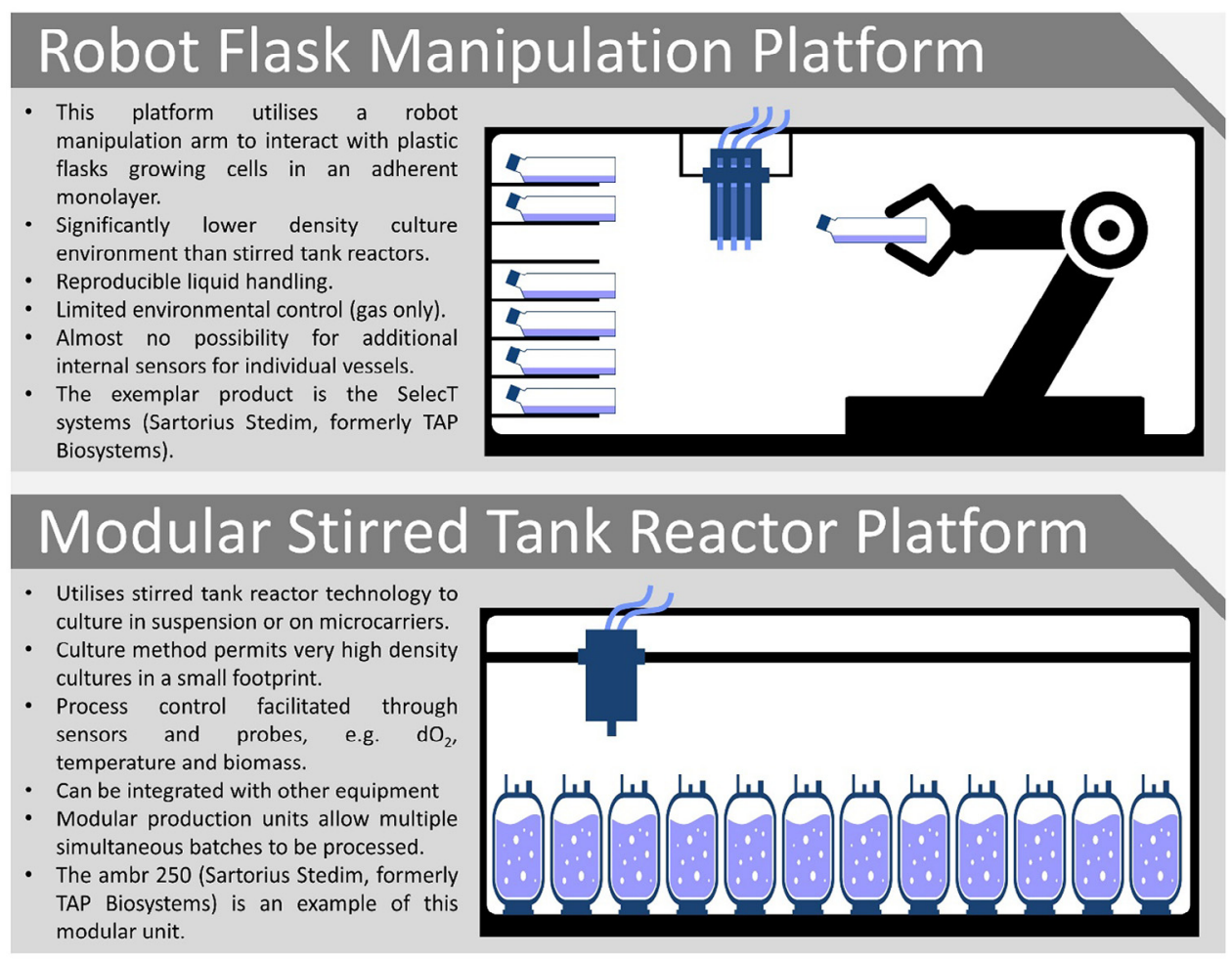

Figure 2. Candidate manufacturing platforms for adherent (monolayer) and suspension (stirred tank reactor) culture of CGTs.

United Kingdom as a whole will possess substantial manufacturing capacity for CGTs. The opening of the ThermoFisher CryoHub to support logistics and delivery of these therapies [16] will enhance the cryogenic supply chain in a centralised manufacturing model. Despite this, certain CGT products would still benefit from being manufactured in or near the clinical end user.

Support for this DCM approach is in part recognised by the report that recommends the establishment of what has become known as 'Advanced Therapy Treatment Centres'. £30 million of Central Government funding has been allocated to establish three of these [15]. These centres are specifically designed to facilitate the creation of viable CGT business models and support commercial manufacture and formulation in a hospital setting. Part of the mandate of the funded centres is to garner operational learning that will facilitate manufacture closer to the patients. This investment will act as a catalyst for adding resilience to the provision of CGT treatments and will add significant value to the UK capability in nearpatient manufacturing.

\section{Regional implications of the shift to high-value manufacturing}

Since the mid-1960s the United Kingdom has lost more than 6 million manufacturing jobs. In the face of cost-competition from low-wage economies such as China, manufacturing in the United Kingdom must compete by emphasising specialised high-value niches where it is able to compete internationally [17].

Across the United Kingdom, the number of manufacturing jobs has decreased substantially, but The Midlands and North have been hardest hit, primarily because they contained a larger per capita percentage share of manufacturing industries than the South. Additionally, these Southern locations were often more able to retain presence in delivery of specialist services or research and development during downsizing operations and thus escaped much of the impact of the downsizing experienced elsewhere [18]. The differences between the regions must be considered in relation to a series of factors, however. These include, on the one hand, the abundance of access to support services and related industry in the South-East and, on the other hand, the accompanying expense of operation that is driven by market forces in relation to those advantages [17].

As the trend toward high-value manufacturing continues, it changes the composition of the workforce [19]. Factories of the mid-20th century consisted of a multitude of workers undertaking a limited range of tasks. The factories for high-value manufacturing in the future will largely consist of automated tasks and the role of the worker will be mainly that of oversight, maintenance or programming. This is a relatively high-skill task and will require a skilled work-force commanding a 
relatively strong salary. This change would benefit many regions of the United Kingdom provided that the regional population has access to the requisite training.

The investment in the Cell and Gene Therapy Manufacturing Facility is an example of the 'agglomeration economy', which is based on the principle that companies operate more effectively if they are near other similar companies and can benefit from shared supply, demand and skilled labour [20]. A variant on this theme is centred on the idea that innovative manufacturing functions best when located next to universities and research environments. Anyone doubting this apparent effect in the biotechnology sector only needs to examine Boston and Cambridge in the United States to witness how the concentration of biotechnology-focussed companies has created an inflection point for the industry like no other globally. DCM offers an interesting alternative paradigm whereby a business can benefit from centralisation of its core facilities while situating ancillary DCM centres in geographically diverse regions close to the end point-of-care. The drive to decentralise could come from tax concessions or other regional government incentives yet would have the additional benefit of providing meaningful employment to other disparate regions.

\section{Materials and methods}

\section{Overview}

Establishing a DCM network poses numerous challenges, yet predicates already exist in allied healthcare sectors that could be used to derive a theoretical manufacturing process and supply chain model [13]. Despite the similarities of these sectors to a potential manufacturing scenario, there are key differences that would influence a CGT manufacturing network [13]. These existing paradigms and guidelines were used to inform the creation of a model and case study examining the manufacture of allogeneic cell therapies in a UK regional setting.

Any emerging business model would have to adhere to current good manufacturing practice (GMP) standards and assure control across a network of facilities. The granular details on how this could be accomplished in the case of DCM are currently unknown, and are likely to remain uncertain for the short term, while the necessary engineering research takes place to allow quality control (QC) and comparability to be enforced across sites using technological solutions [21]. The situation may be likened to an equation with too many unknown variables and this gives the opportunity to consider what the economic and operational impact would be for some of the possible options. We offer this article to inform the growing industrial and academic dialogue about which operational models hold the greatest potential for healthcare, employment and economic impact in regional development. We believe that there is currently an opportunity for stakeholders to shape policy as the eventual regulatory environment is likely to be driven by a growing confidence arising from the combined opinions of researchers, equipment manufacturers, product manufacturers and regulators working together to scope out suitable models and to deliver sustainable clinical success.

A range of business pressures were examined, including the role of the geographical region in shaping facility rollout, economic decisions affecting QC strategies, in-process losses (of the active pharmaceutical ingredient, in this case, the cell, and the final drug product), staffing across the network and finally the directionality and frequency of shipping.

\section{Model design}

A process economics modelling tool was developed to examine a network of DCM facilities organised around a supporting hub facility. This model consists of a graphical user interface (GUI) developed using the Microsoft Excel platform with integrated Visual Basic for Applications (VBA; Microsoft Corporation) script. This model uses an established database of parameters combined with user-specified variables to predict technical manufacturing outputs as well as financial performance. Individual facilities were examined as points in a manufacturing network to build a picture of a networked manufacturing strategy.

Required manufacturing capacity was calculated based on the number of patient doses required across all geographical regions served by a DCM 'node' per year. The network comprised 'central hubs' from which starting materials and optionally services are supplied at the level required for regional manufacturing sub-facilities or 'nodes' that manufacture appropriately sized batches for regional supply to networks of regional users. The central hub facility was specified to produce seed doses as an intermediate product 'kit' for onward expansion at decentralised node facilities, assuming $20 \%$ excess doses each year. Biological characterisation of cell sources was used to establish lot size yield projections and to establish the resource consumption and equipment requirement of the upstream and downstream processes. Baseline values for facility size, office space and staffing requirements were established in the model.

Cost of goods (COG) of a particular process configuration consists of annual direct costs (materials, labour staffing and QC) and indirect costs (facility and equipment costs and loan servicing) as described in Figure 3. Facility and equipment were amortised over 10 years as suggested by the Worldwide Capital and Fixed Assets Guide [22]. Loan agreements were 


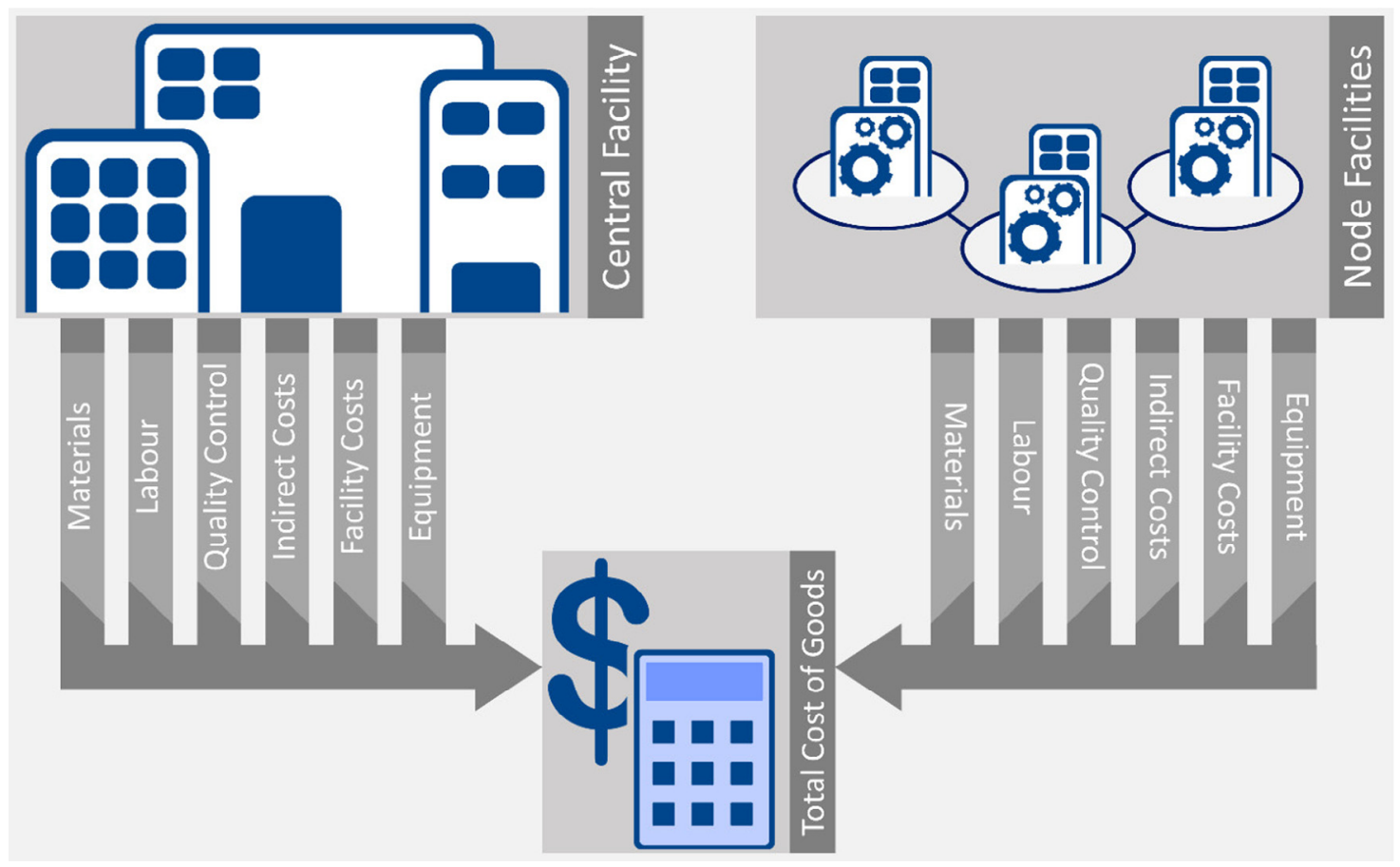

Figure 3. COG calculation methodology for the DCM network. In brief, materials, labour (including training), QC (as a subdivision of labour and materials), indirect costs, facility costs and equipment costs were calculated for the central and decentralised node facilities. These were then combined to calculate the overall total COG for the whole DCM network. Labour costs arise solely from employment of full-time staff as described in the Supplementary Material; there are no part-time or indirect labour costs accounted for. Further information can be found in the Supplementary Material.

assumed at 10 years at $5 \%$ interest. An investment discount factor was not applied and could be factored in later as required. Staffing costs are calculated per salaried full-time individual. Administrative costs are captured solely in the employment of administrative staff and associated training, not through any other costs or multipliers. Research and development and sales costs are not captured by this model. A further breakdown of costs is located in the Supplementary Material. The breakdown of costs describes the staffing levels at each facility with the staff expected to perform all ancillary services such as health and safety, regulatory support and environmental monitoring. In certain cases, additional costs could be considered necessary.

\section{Model sources}

Tables of all process and cost assumptions used within the model are detailed in the Supplementary Material. Medical technology company data were provided by the Association of British Healthcare Industries (ABHI) and the location data of cleanrooms from the Cell and Gene Therapy Catapult Annual Review 2016 [23].

Salary bands were based upon the National Health Service Pay Scales. These were adjusted to reflect regional variations using the Annual Survey of Hours and Earnings (ASHE)-Office for National Statis- tics. These were then combined to create salary banding with regional disparities.

Estimated population densities for UK regions were identified using PopulationExplorer [24] (Kimetrica) and Landscan [25]. These tools were used to identify high-value target areas for placement of the 'hub' or 'node' sites and are presented in Supplementary Figure S1.

Business Ratable Values were obtained from the Valuation Office Agency 2005 and 2010 Local Rating Lists and were adjusted using the relative national change to account for the 2017 changes [26]. A multiplier was extracted to apply to each of the UK regions.

Business rental values were obtained from Colliers International National Office Rents Map 2016 [27]. Service charges were obtained from Simon Korn Commercial Property Consultants for London and extrapolated for other regions [28]. Values were for a 'grade A' new-build unit in a prime location.

Case study

DCM is a significant departure from the traditional centralised manufacturing explored in most process economics and COG case studies. The case study presented here is informed by previous exploratory research detailing the potential operational scenarios for businesses engaging in DCM [29]. Business rates, 


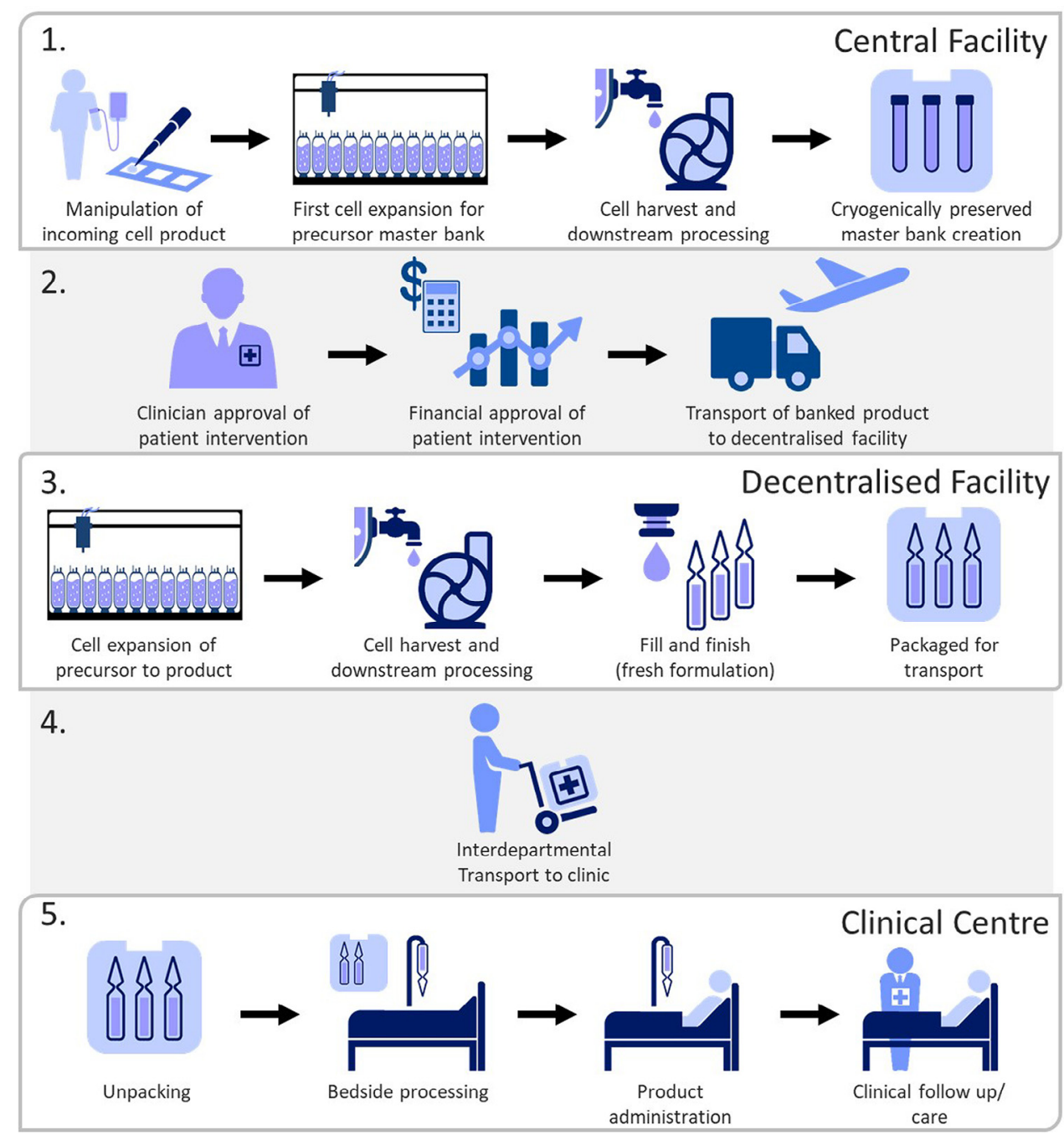

Figure 4. Process flow diagram outlining key features of the hypothetical MSC case study. In brief, the incoming allogeneic cell source is expanded in the central facility to create the cryopreserved master bank. Upon receiving approval for the intervention, the banked product can be further expanded to produce the final fresh formulated product. This is then transported the short distance to the clinic where it is prepared for administration by the clinician.

regional wage disparities, rental rates, service charges and population metrics used are described in the Model Sources section.

The manufacturing process describes a theoretical allogenic or partially patient-matched mesenchymal stromal cell (MSC) therapeutic (Figure 4). The therapeutic is manufactured in a DCM 'node' supported by the centralised 'hub' facility. The benefit of choosing a universal-donor therapeutic model rather than patient-specific, is that one lot to one patient begins the study with the simpler case before turning in due course to the complexity of autologous supply with significantly increased costs $[30,31]$. These costs are magnified further with DCM due to QC, transportation and logistics [21].

Scalable cell expansion technologies have been identified as a key factor in driving down the manufacturing costs for CGTs $[21,32]$. For DCM, these scalable platforms are likely to be smaller scale and modular with isolated product streams to separate out the batches and to allow efficient line-clearance procedures [33]. We have previously examined putative manufacturing platforms for these products [6] and for the current research we have costed a modular, scaled-out microcarrier-based expansion platform adapted from published works [34]. This hypothetical manufacturing platform uses small-volume $(250 \mathrm{~mL})$ selfcontained process modules that are controlled in batches of $10-30$ by a central control system. This platform is ideal for the 100,000 cells/kg body weight $(75,000,000$ cells total per patient) dose described in this manufacturing case study. This case study assumes 500 doses manufactured at each location per year (5000 total/annum). There is no accounting for dose 
ramp-up or idle capacity accounted for in this model. Because the decentralised model looks to minimise idle capacity, potential cost reductions could be realised through efficient use of the high-cost fixed assets [35], although this must be balanced with the increasing challenge, and potentially significant cost of coordinating production and supply from distant parts of the network. A process flow diagram outlining the hypothetical manufacturing strategy described herein is presented in Figure 1.

DCM splits manufacturing capacity across geographical regions and, in doing so, imposes constraints on the structure of a company. Several factors must be considered when identifying which geographical regions will not only have the demand, but also the supply of strategic assets, transportation routes, resources or people. In brief, these consist of demand (population within serviceable areas of the decentralised node), supply of strategic assets (international transit hubs) and workforce (supply of highly trained individuals within the medical technology sector). These factors were used alongside the Science and Innovation Audits [36] to identify putative regional manufacturing centres across the United Kingdom (Supplementary Figure S1). The selected sites provide catchment for $60 \%$ of the United Kingdom with population outside a direct catchment area still being represented locally by a node within their extended area.

\section{Results and discussion}

\section{Regional variations and pressures}

Across a DCM network, the nodes and a hub are situated within a variety of geographic regions. These regions have different environmental factors, each of which contributes to differing cost and social pressures on the business [37]. Some of these trends are clear; for example, land and wages are dramatically higher in many Southern regions when compared with their Northern counterparts. Other trends are less obvious, such as the underlying benefits businesses receive when located in regions densely populated with similar businesses.

Each geographic region is likely to have differing rents, business rates, service costs and staff salaries. These factors combined have an effect on the overall cost of situating a business presence within that region. The variance between these costs across regions of the United Kingdom is shown in Figure 5 for the central hub facility (A) and the decentralised node facilities (B). Understandably, London is significantly more costly than the other regions, although, perhaps surprisingly, other regions show relatively low variation. Regional wage variation is the largest source of cost differential and it is thus unsurprising that the differ- ence between the costliest and least costly regions is greatest for the central facility compared with the provinces where staff costs are a greater proportion of total ongoing costs. It is important to note that DCM relies upon local skills being available. These data do not incorporate any expenditure that may have to be allocated to either entice talent to regions that lack the sufficient skills pool, compete for existing skilled individuals in a highly competitive environment or retrain individuals once the facility has been established.

The role of London in contributing to the efficiency of an operation can be substantial. The abundance of transport links for air, ground and sea freight, the internationally renowned specialist hospitals and the associated abundance of skilled labour make it a destination of choice for high-value, lowvolume, high-margin personalised therapies. However, the balance of costs may not work so well for lowermargin, high-volume products. For a DCM paradigm, each facility is part of a wider network and thus should not be considered in isolation. Figure 5C presents these facilities as an integrated network with the central facility moving between each respective region. When examining this extended decentralised network, it becomes clear that, if the central hub facility is situated outside of London, the business can reap significant savings. Because there is still a node present within London, this saving is made while still providing the same clinical provision to the region. When examined on a price per dose level the greatest savings can be gained by not situating within London. COGs within London are approximately $£ 2000$ per dose whereas the regions range from $£ 1795$ (Nottingham) to $£ 1850$ (Edinburgh). This obviates the easiest savings that are gained by situating outside of the London area with smaller incremental savings to be made between competing regions.

Although at first glance these savings may seem minor, particularly when examined as a cost per dose, it is illustrative to examine what the savings thus reaped could be re-invested into. If the primary hub is placed outside London, between 25 (Edinburgh) and 41 (Nottingham) extra operators could be employed to manufacture product (Figure 6A; defined as junior operators, excluding training costs). Alternatively, in a DCM network, the dominance of automated manufacturing platforms may make investment in more manufacturing process modules attractive (Figure 6B; defined as $1 / 24$ th of an additional bioreactor platform). In this scenario, between 25 (Edinburgh) and 34 (Nottingham) additional process modules could be integrated across the wider manufacturing network.

The COG savings must be considered as part of a wider business case considering clinical indication, patient volume and reimbursement price. With a theoretical reimbursement threshold for this product of 

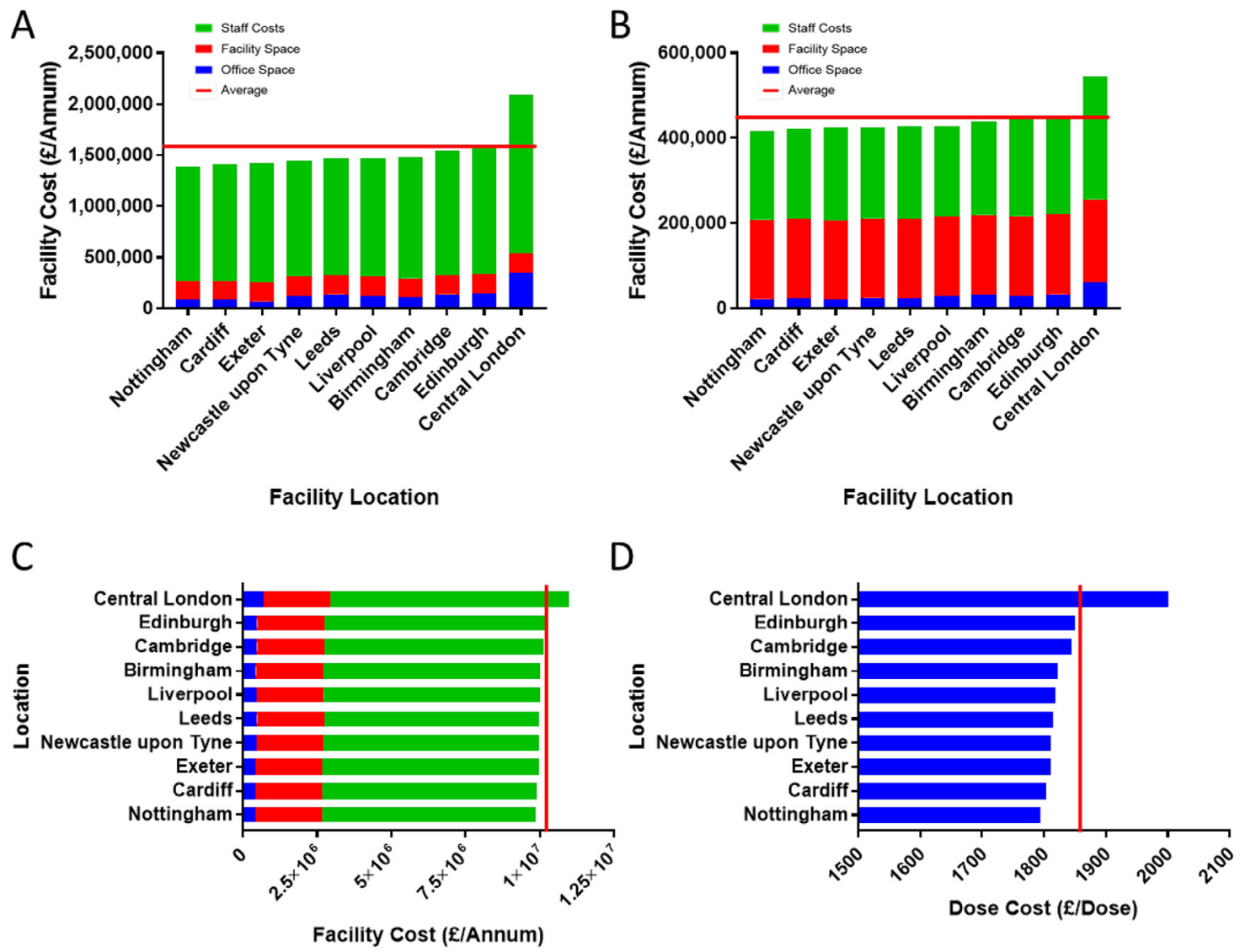

Figure 5. Economic pressures affecting business sites and regional placement of a manufacturing network. Location of a central facility in a geographical context can be seen to have a profound effect on running costs per annum due to a combination of increased property values, service costs and business rates (A). Similar trends are present for smaller DCM hubs (B) with London being the highest cost location. When these values are used as part of a larger decentralised network (C), it becomes clear that if the larger bulk of the business is situated outside London, significant savings can be made with the same provisioning of end-point clinical products. In a price per dose cost, it is obvious that although there is value to be had situating in cheaper regions, the main savings are had by not situating in London (D). Costs comprise yearly office space costs, yearly facility costs (excluding materials), business rates and service charges as well as staff costs. Average costs are signified by the red line. (For interpretation of the references to colour in this figure legend, the reader is referred to the web version of this article.)

$£ 50,000$, the margin in London would be $96 \%$ versus $96.3 \%$ in Edinburgh. This presents a large COG saving, yet this may present a poor business case with little difference between the two locations. This highlights the importance of both considering COG as part of a wider business case, but also the likely necessity of additional regional investment factors to drive DCM.

It is important to remember that cost alone is not the only determinant of where to situate components of a decentralised network. London has significant financial costs associated with it that drive up the cost of doing business. However, London benefits from a high density of technical skill, but also easy access to extrinsic aspects of the business. Examples include easy access to some of the world-leading clinical centres and universities, financial businesses, venture funds and regulators. These assets concentrate money, staff, expertise and key management skills required for businesses to thrive and reduce the overhead cost of simply 'doing business' in this sector [38].
Although this is a self-reinforcing attraction for businesses to situate their primary premises within London, efficient transportation networks have minimised travel times to the point where regions immediately north of London are benefitting from the spill-over of the high concentration of these extrinsic factors. Indeed, the Cell and Gene Therapy Catapult Manufacturing Centre is a case in point, retaining a presence within the Capital yet situating a manufacturing centre further north (yet still within the 'Golden Triangle').

The United Kingdom has a long history of policymaking geared toward regional development dating back to the 1930s [17]. High-value manufacturing undoubtedly has a strong part to play in rebalancing the economy and contributing to economic growth of the United Kingdom [39]. However, both conventional wisdom and global trends highlight the importance of specialist hubs such as Boston and Cambridge in the United States, which are able to readily attract companies from the surrounding area. Recent 

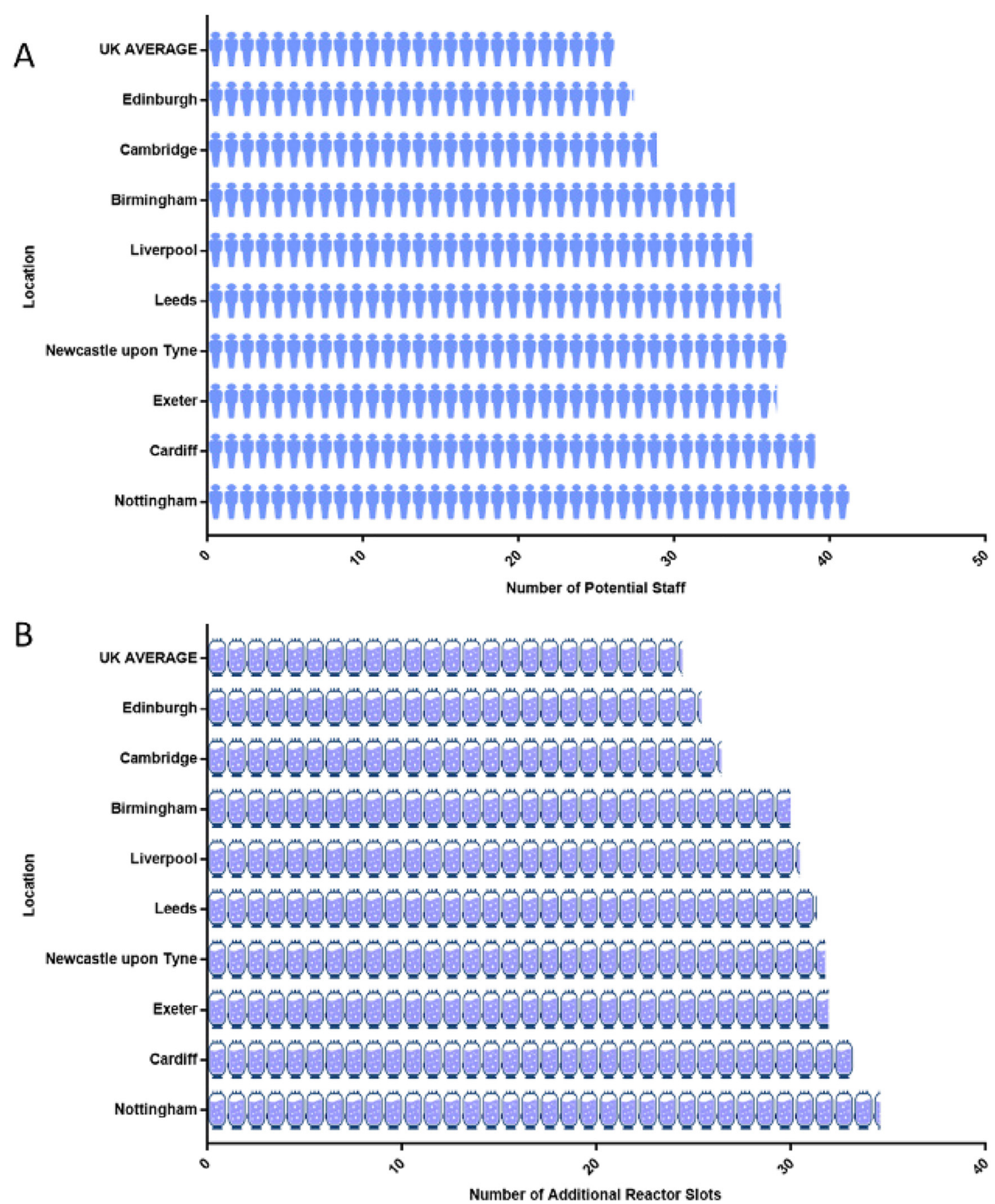

Figure 6. Visualising the potential savings realised through smart geographical business placement. If the main manufacturing hub is placed outside London, between 25 and 41 extra operators could be employed across the decentralised network (A). Alternatively, in a chiefly automated production system, it could be possible to expand production by $24-35$ extra reactor vessel modules, which each allow another production lot to be run in parallel (B). Assumptions: staff salary band $£ 27.3 \mathrm{k} /$ annum, reactor vessel module cost $32.7 \mathrm{k}$. This is an illustrative example and expansion would be driven by patient projections.

high-profile examples of this have included Blue Rock Therapeutics which moved from Toronto to Boston to tap into not only the technical expertise, but also the wider entrepreneurial environment. This effect is reflected to a lesser extent in the Cambridge, Oxford and London 'Golden Triangle' in the United Kingdom.
This area similarly is able to attract business and inward investment. DCM with a 'hub' in Cambridge (United Kingdom) and 'nodes' across the United Kingdom could both benefit from this 'agglomeration economy' and offer manufacturing employment across the UK regions while providing a viable trade-off between 

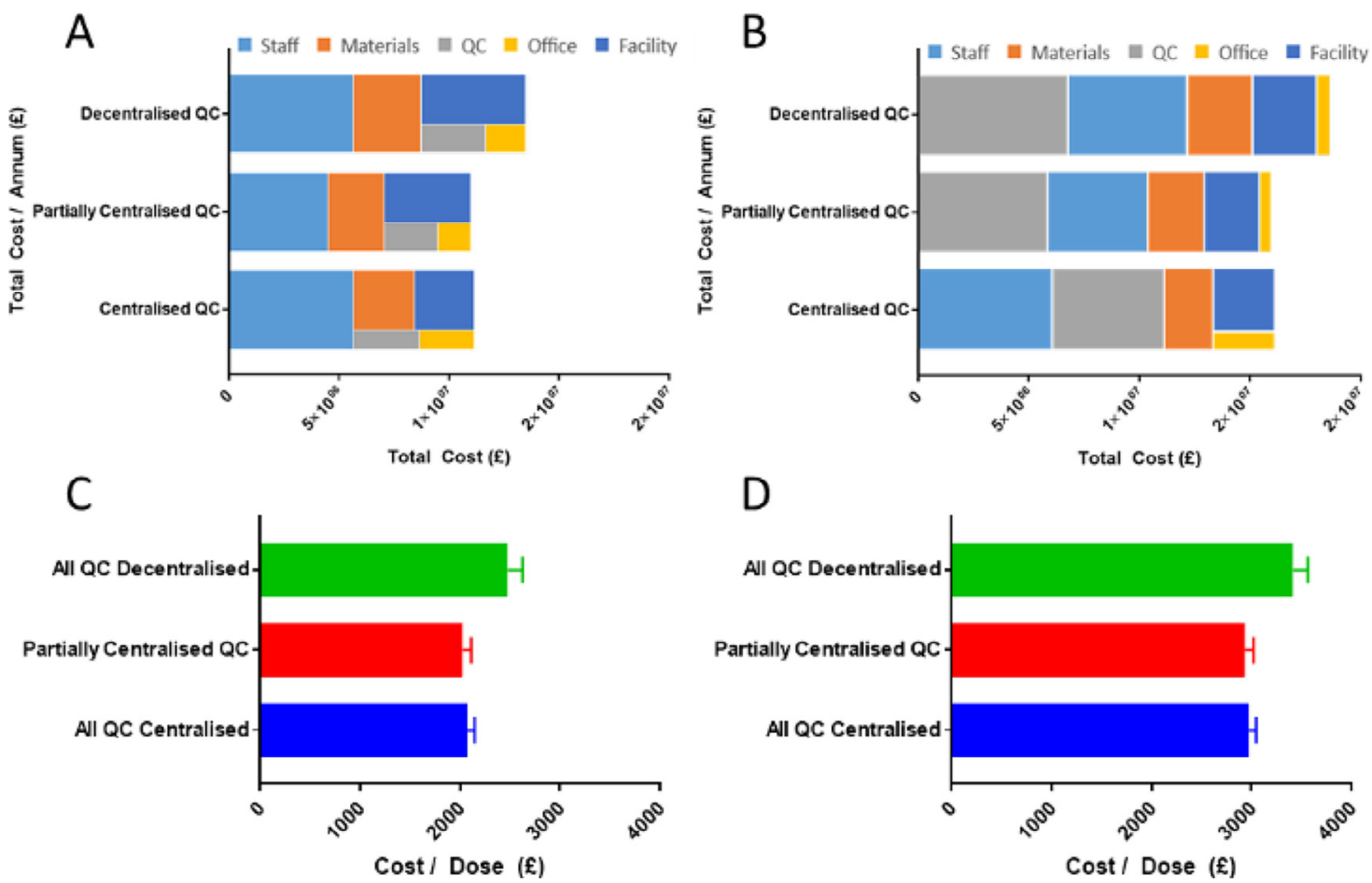

Figure 7. Economic considerations of differing QC strategies for DCM networks. Two QC assay panels based on current commercial MSC product testing were examined. These were costed at approximately $£ 6,000$ and $\sim £ 37,500$, respectively. Three QC strategies were examined: "fully decentralised" (staff at each sub-facility), "partially centralised" (some staff at each decentralised facility supported by centralised staff) and "centralised QC" (all QC is performed centrally). The cost of QC as a total COG is presented as a treemap highlighting the constituent values for the $£ 6,000$ (A) and $£ 37,500$ (B) QC panels. The total dose reimbursement cost for products produced across the decentralised network is presented for the two $£ 6,000$ (C) and $£ 37,500$ (D) QC panels highlighting the variation in production costs across regions. Centralised QC location is the Cambridge hub facility.

economic prudence and sound business management. Consequently, for the subsequent model outputs, the decentralised network will assume that Cambridge is the decentralised 'hub'.

\section{Decentralisation of $Q C$}

As manufacturing strategy progressed from preindustrial bespoke manufacture towards industrialised batch production, the demand for product variation decreased. Since the 1990s, the desire for flexible manufacturing, able to respond continually to changing markets, has increased [40]. DCM represents a return to small-scale manufacture and much of the research is geared toward creating the manufacturing platforms able to perform the process. Yet, one of the key uncertainties remaining is how to maintain quality control from a distance [41].

Current approaches to allogeneic CGT manufacture require a panel of $\mathrm{QC}$ tests that require not only specialist physical resources, but also appropriate significant technical expertise [42], which may not be locally available at each site. This represents a significant investment in both resources and staff at each location, to provide the level of QC characterisation that is suggested to be necessary [42]. Thus, there is significant advantage for DCM if it were possible to centralise QC resources. The obvious example would be locating the QC facilities at the 'hub' with decentralised 'nodes' providing material or data collected locally.

For this case study, three options for QC were examined: fully centralised, fully decentralised and partially centralised. The QC profile was modelled on a real-world assay panel and sub-divided into a basic panel of current practice (cost approximately $£ 6,000$ per batch) and an extended panel including emerging -omics and genetic testing (cost approximately $£ 37,500)$. These are further described in the Supplementary Material. The total COG over a year is presented for the basic panel (Figure 7A) and extended panel (Figure 7B). The per dose cost of these three QC strategies are presented (Figure 7C and 7D). These demonstrate that significant cost savings can be realised through centralisation of QC. Although this is unsurprising, it is valuable to realise that equivalent savings can be realised through only partial centralisation of QC.

When further examined, the total contribution of QC from each aspect of the decentralised network can 
be visualised. As QC is increasingly centralised, more of the QC burden falls on the centralised hub. Surprisingly, however, these data suggest a hybrid QC strategy may not only be easier to implement, but may also allow for equivalent cost savings when compared with complete decentralisation of QC. These savings are hypothesized to be enabled by using technical staff to run the simpler assay panel locally while the complex panel is outsourced to the central facility. Thus, a relatively cost-efficacious labour force provides local assay expertise while the challenging assessments that require expensive capital expenditure and costlier labour are able to benefit from the centralisation cost-reduction methods. This practice of releasing 'at risk' [1] is an accepted practice in radiopharmaceuticals and oncology and this effort to partially decentralise would allow the local assay panel to build up enough confidence to release the product on the assumption that the full assay panel will be completed to validate the release criteria.

Although these data provide key insight into the potential high-level costings of these three approaches, it is important to keep in mind that it is not currently clear whether this approach would be feasible from a technical or regulatory compliance perspective. With a typical time window for in process QC testing of samples of 2-3 hours with current testing procedures, it would be challenging to transport samples and receive meaningful insights. Similarly, there is a very real possibility that for some tests it may be more cost effective to outsource to a third party.

\section{The impact of product loss from the manufacturing value chain}

Current culture platforms are far from perfect and deficiencies in manufacturing result in lower cell yields per cycle and consequently a higher product price $[14,43]$. Similarly, CGT products are exquisitely sensitive to uncontrolled variations in the distribution chain. Thus, measures must be taken to provide robust environmental control not only during the manufacturing or culture period, but also during any logistical or shipping steps. The former has received substantially more attention and investment and potential purpose-built culture environments are beginning to be available for CGT manufacture. Historically the issue of the CGT supply chain has been relatively under-funded [44] and only recently have substantial product advances and investment decisions beyond mandatory characterisation occurred [45]. These include dedicated facilities such as the Fisher CryoHub for storage, distribution and logistics, services such as Cryogatt RFID and TrakCel for audit and chain of custody and products such as the Asymptote Thawer for automated reconstitu- tion. Despite these advances, product loss within the manufacturing value chain remains a substantial threat to efficient and cost-effective production worthy of examination.

When modelling the cell manufacturing process, it was observed that small to moderate cell losses of up to $35 \%$ were tolerated in the manufacturing process itself for the three MSC cell types (Figure 8A). Losses up to $35 \%$ did not increase the final dose price significantly, but at $>35 \%$ in-process cell loss, doses quickly increased in cost and this effect was magnified for cell types with poorer growth kinetics. This relative cost-susceptibility of low expansion-potential cells is due to the fewer doses achieved per lot with similar resource expenditure on consumables. Manufacturing research and appropriate culture equipment able to administer fresh media or other consumables such as growth factors only when required rather than to a fixed menu would reduce this cost differential, but these hypothetical systems are yet to be implemented. Loss of a fresh (not frozen) product postmanufacture was examined (Figure 8B) and demonstrated an increase in cost per dose across all cell types.

One of the suggested drivers to decentralise [29] is to minimise the end product logistical burden and associated product loss. Product loss was plotted against increasing numbers of technical operator-level staff at the decentralised node facility (Figure 8C). This was plotted against increasing post-manufacturing product loss. As more staff are employed at the central facility, the total COG and subsequent dose cost increases. Interestingly however, dose loss in transit is a less important influence on COGs and, assuming in-transit losses can be kept at $50 \%$ or below, reduction of staff at the DCM facilities becomes a much more influential cost-reduction measure. Also of note is the relative absence of cost difference between the 'minimal', 'normal' and 'high' staffing levels at the central facility. This suggests that outsourcing tasks such as QC to the central facility as a means of reducing the staffing footprint at the decentralised facilities would be a commercially viable option.

\section{The impact of product loss during distribution}

Even with DCM, it is necessary to perform a certain level of shipping for each product manufacturing cycle, albeit over small distances to regional clinical centres. Depending on the exact business model and QC strategy, the decentralised network may comprise of anything from a unidirectional hub-to-node, lowcost cryogenic shipping strategy to a multi-directional approach with several shipping cycles per dose produced. The causes of multi-directionality in the logistics chain are highlighted in Figure 9. 

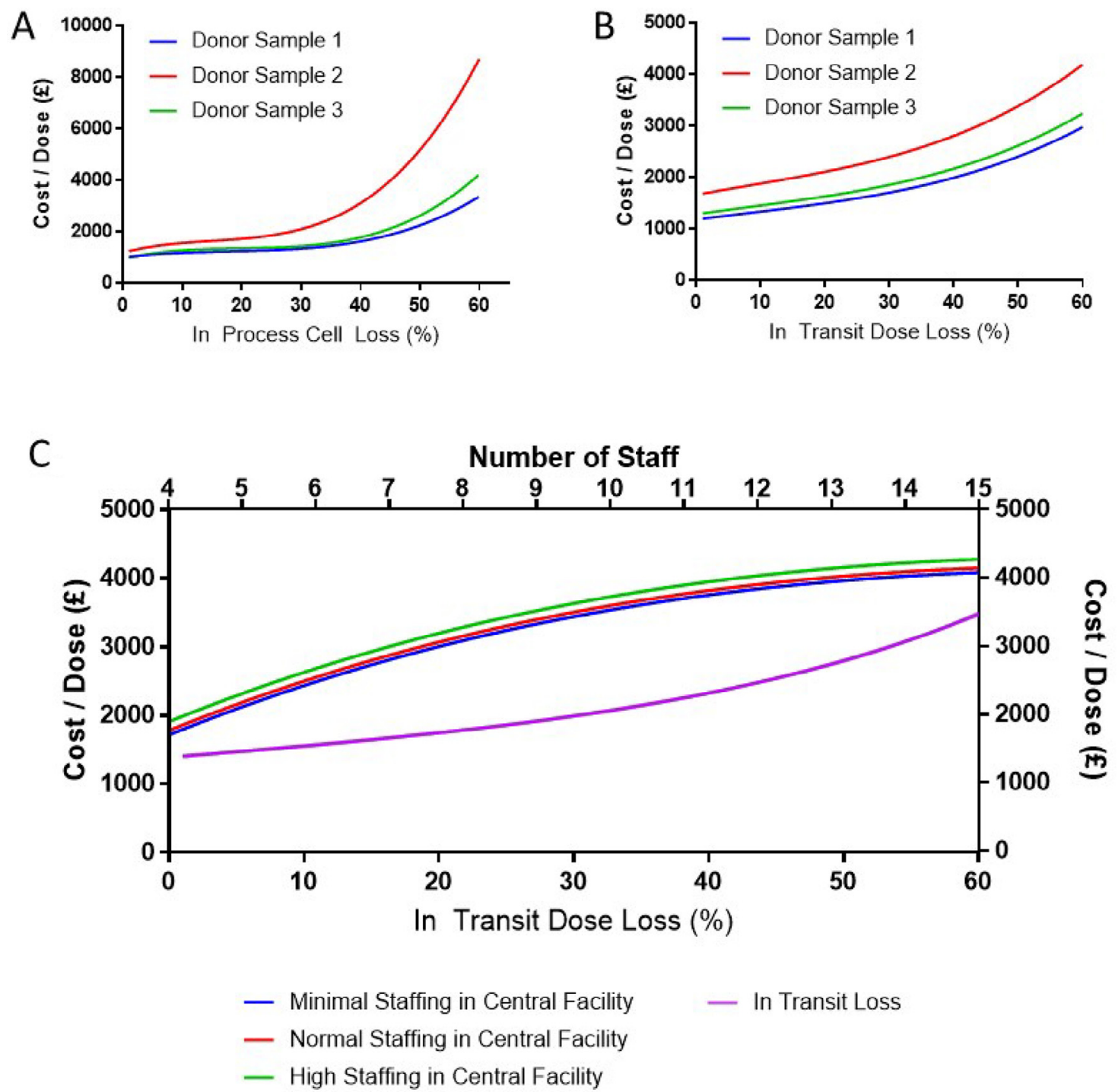

Figure 8. The effect of cell and product loss during the manufacturing value chain. Small to moderate cell losses (up to $35 \%$ ) in process do not profoundly shift the cost per dose (A). Product loss post-manufacturing was examined (B). Increasing in-transit dose loss from a centralised facility to receiving clinical facilities was plotted against the cost of employing increasing numbers of staff at decentralised manufacturing sites across the network (C). Low staffing in the central facility consists of 17 staff members, medium is 22 members and high is 32 members. The lowest decentralised staffing consists of one administrator, one technician and one of each junior, standard and senior operator. The highest decentralised staffing consists of one administrator, one technician, three senior technicians, four junior, two standard and three senior operators as well as two senior scientists. Additional support staff may be seconded for tasks such as cleaning and monitoring at additional cost from the adjacent clinical facility.

CGTs are a 'living drug' and sensitive to environmental conditions, such as temperature and humidity, all of which can have an impact on the viability of the drug and its effectiveness. Controlling these conditions are arguably more challenging with 'fresh' less stable, non-cryogenically preserved cell products due to the narrow physical and time parameters required for success. These products essentially remain in culture during transport and require active management of the product. Specialist packaging containers and environmental management products exist that aid in fresh shipping but if the product has a time-sensitive shelf-life then costs can quickly mount up for dedicated transportation over anything other than short distances. The cryopreservation of products requires expensive equipment within the distribution chain, yet increases the maximum transit duration dramatically, which allows pooling of deliveries and thus a reduction in freight costs (Personal Communication, Steve Langron, Lime Associates). In this case study a 'fresh' therapeutic formulation is examined to evaluate the impact of potential cost reduction methods. Both per-dose costs and strategies to reduce the cost by bundling doses into multi-product shipments are 


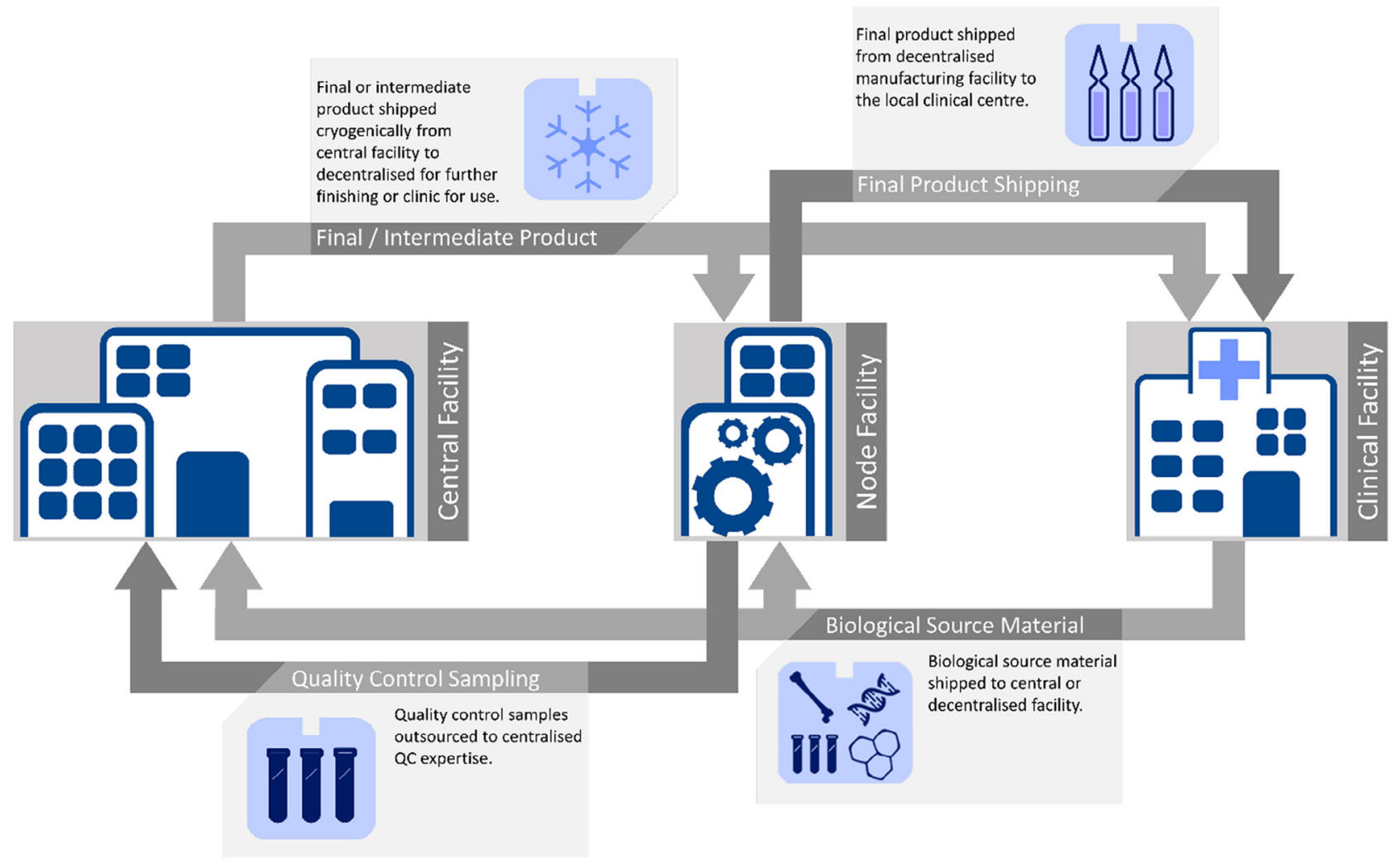

Figure 9. Levels of directionality and complexity in the logistical chain of a DCM network highlighting the potential movements between facilities. Not all paths may be present in all DCM scenarios. Materials can flow in multiple directions from clinic to node to central facility depending on the manufacturing strategy of the product. It is important to note each direction of travel may occur more than once, several batches of QC may be outsourced, or multiple treatment doses shipped to the clinic in set intervals.

presented (Figure 10A). By packaging doses into shipments, the increased cost burden arising from increased travel directionality of materials flow between central and decentralised node facilities can be offset. The regional cost per dose is largely uniform across regions, reflecting the similar cost between manufacturing sites (Figure 10B).

The relationship between individual product loss from a shipment and whole shipment loss (e.g. due to poor management of transit) was investigated (Figure 10C). Bundling of doses into shipments helps to reduce the chances of doses falling out of specification. On the other hand, dose bundling increases the cost sensitivity if a whole shipment falls out of specification. These data suggest that if $10 \%$ of shipments are routinely lost or late, bundling four rather than eight would be financially prudent. It is important to note that the number of doses able to be pooled into one container will be driven not only by costs, but also by patient volume and ability to receive samples at the treatment site. All of these data assume adequate transit trials have been completed to validate the shipping conditions for the product. Similarly, many of these costs may present as lower values in the form of excess in- surance payments because it is likely a manufacturer will insure against this risk.

\section{Logistics, $Q C$ and flexible decentralisation}

Undoubtedly enacting a full DCM network is a challenging prospect due to the substantial shift it represents from traditional manufacturing practices. Both efficient logistics and QC are critical aspects in evaluating the feasibility of the potential network but taken together they introduce an important question: How far should the value chain decentralise to gain the purported benefits while avoiding the challenges? This hybrid decentralisation approach is informed by the relationship between QC COGs, logistical COGs and necessity for localised responsive manufacturing. A sample partially decentralised QC process is highlighted in Figure 11.

One of the key questions remaining is that of comparability between sites and ensuring that the material that left one site is equivalent to that entering the next. This will require comparability studies, but past experience would suggest that this logistical burden is manageable using both cryogenic and refrigerated 

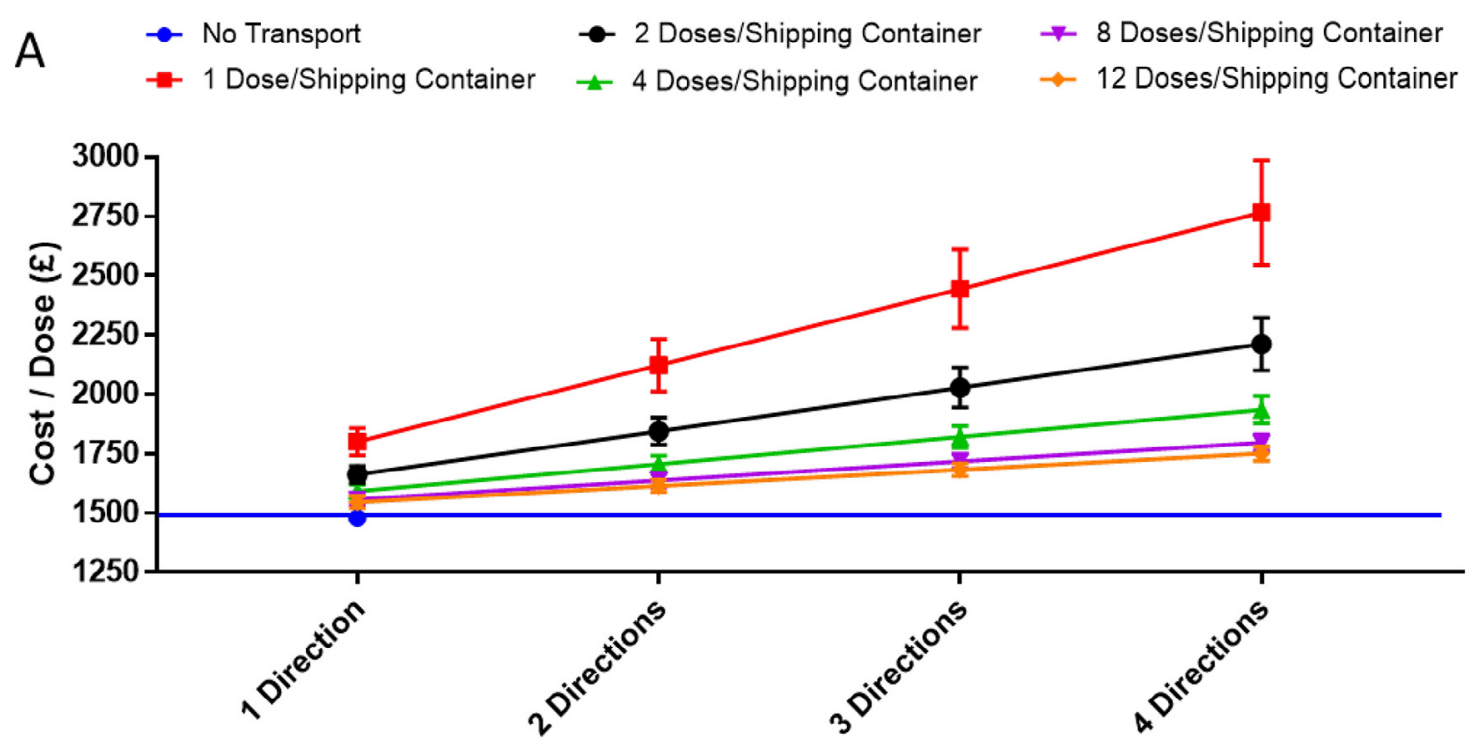

Shipping Frequency
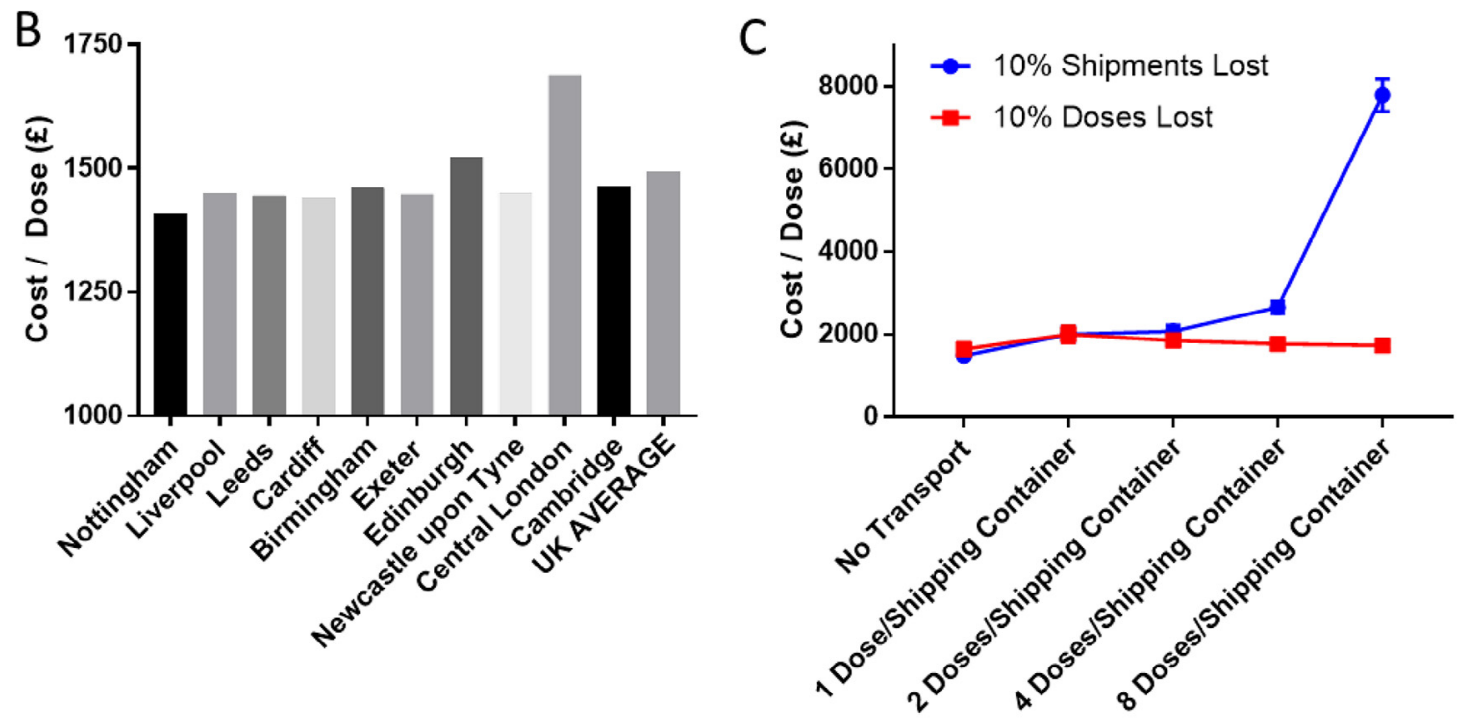

Figure 10. The effect of product loss through extraneous issues, such as loss and damage in the distribution chain versus doses falling out of specification due to in-transit delays. As the frequency of product or dose transit goes up, the cost per dose increases, but this can be offset by packaging doses into shipments (A). The cost per dose (without shipping) is largely uniform across regions (B). As doses are packaged into shipments (C) the cost impact of failures in the distribution chain are magnified (blue line). However, an efficient transport chain that minimises loss of product during distribution can help overcome increasing costs due to individual dose loss (e.g., falling out of specification mid-transit due to unexpected delays; red line). (For interpretation of the references to colour in this figure legend, the reader is referred to the web version of this article.)

storage shipping in tandem (Dendreon) $[46,47]$ or refrigerated storage alone (Carticel and ChondroCelect) [46]. Similarly, these data presented here suggest logistical COGs are not a large component of total COGs and both of these factors are likely to improve with the increased investments recently in logistics and supply chain management. This leaves the requirement to manufacture locally and the feasibility and cost of administering $\mathrm{QC}$ as the key trade-offs for opting for DCM.

This research has suggested a hybrid QC strategy is practical from a COG perspective. The question remains, will the regulator have an appetite for this flexible hybrid QC strategy? We would argue that the necessity for this in biological products is already appreciated [48], yet the paradigm already exists in the practice of releasing at risk for oncology products. These are allowed to be released to the patient after fulfilling a minimal release panel on the proviso the full followup panel is completed post-use. Based on these data and the wider experience of related fields, DCM using a hybrid QC approach may not only represent a costefficacious approach, but also a potentially feasible one. 


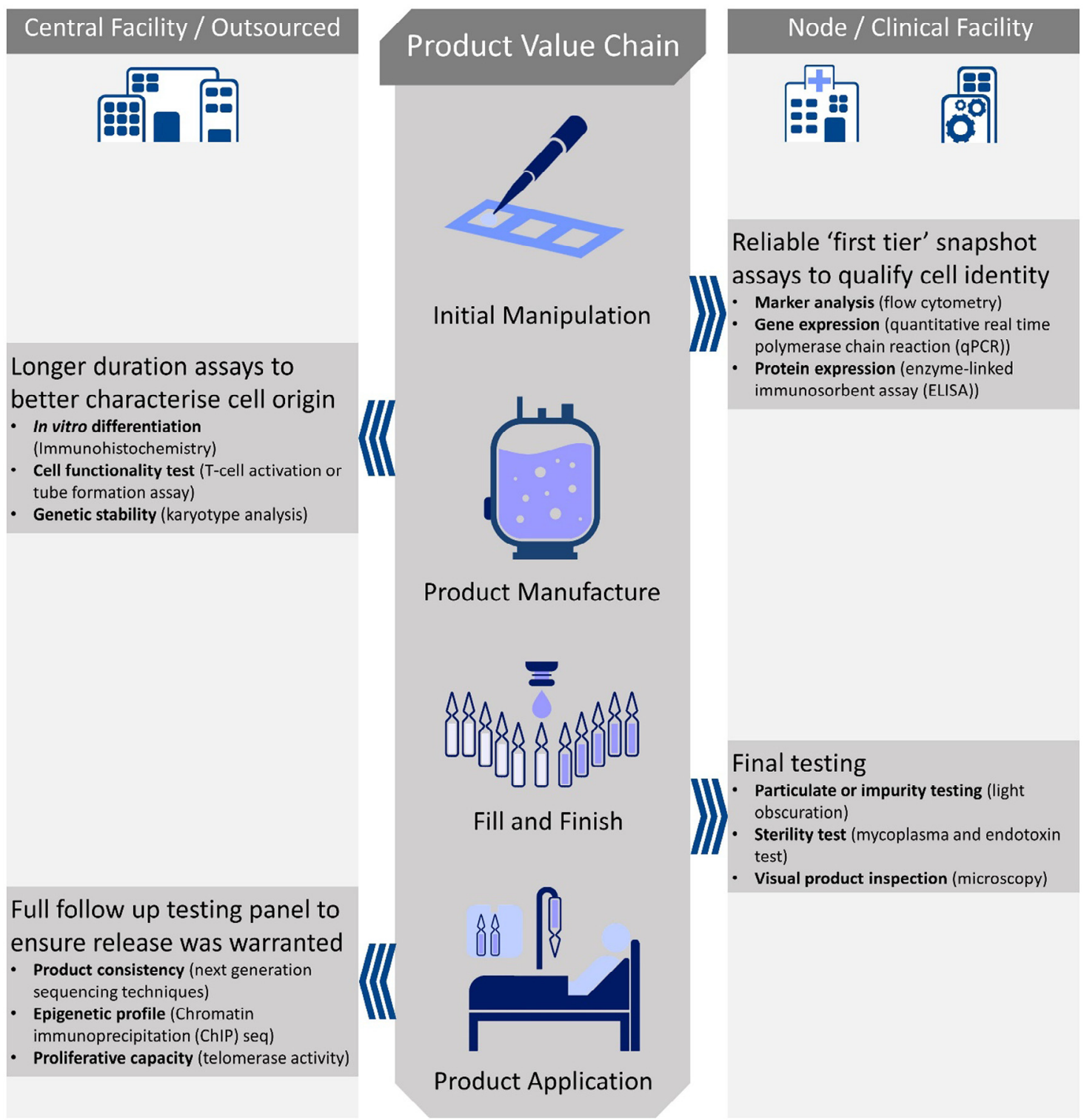

Figure 11. Illustrative diagram of a QC panel for a mesenchymal stromal cell (MSC) therapy. Simpler tests requiring fewer specialised personnel and items of equipment are located at the node of clinical facilities, whereas the more complex, longer duration and costly assays are outsourced or returned for analysis at the central facility. In this scenario, the decentralised facility would require QC laboratories, operated under appropriate GMP requirements. Additionally, many of the tests are unable to give results in real-time and thus product may have to be released at risk.

\section{Conclusions and forward-looking statement}

DCM is an attractive proposition for personalised medicine. In this period of growing concern over efficient use of energy, avoidance of waste and the environmental impact [49] of long-distance, temperaturecontrolled shipping [50] there is an extra driver to manufacture close to the point of use.

A hub-and-node model of operation can be attractive because it is a vehicle to drive regional development and job creation and can be appealing to patients who wish to avoid travelling long distances for treatment. The specialist treatment centres put forward by Porter et al. [51] can be regarded as the forerunner of this approach to the manufacture and application of cell-based therapies if it were to be integrated with a small, specialised manufacturing unit as the 'node'.

In the United Kingdom there is increasing opportunity and appetite to explore this route to market access using private and public investment sources [15]. It is important to right-size the facilities to make them sustainable. We have begun to examine the cost implications of some of the underlying choices because this is the economic foundation of the operational design. These economic insights into COG must tie into the clinical indication, patient volume and 
reimbursement price to formulate sound business cases that are driven by an analysis of all these constituent parts, not just the underlying COG.

The next stages in this process will be to look at the interface with the clinical pharmacy services and procurement to ensure smooth hand-offs in the chain of custody, to identify the appropriate QC arrangements with supporting technology and to find the point in the mechanisation-automation spectrum where there is a sweet spot between the cost of technology deployment and the appropriate confidence in process comparability site-to-site.

\section{Acknowledgments}

This study was supported by an Engineering and Physical Sciences Research Council (EPSRC) Engineering Tissue Engineering and Regenerative Medicine (ETERM) Landscape Fellowship grant (reference EP/ I017801/1) and an EPSRC Fellowships in Manufacturing grant (Nicholas Medcalf; reference EP/ K037099/1). The authors would like to acknowledge the support of the Redistributed Manufacturing in Healthcare Network (RiHN) for their support in coordinating expert meetings. The authors wish to thank Sartorius Stedim for providing insight into manufacturing costs. The opinion reflected in this report is the opinion of the authors and their interpretation and aggregation of the opinion of the individual thought leaders as members of a selected expert reference panel for RiHN. It does not represent the views of their employers or any organisations they may represent

Disclosure of interests: The authors have no commercial, proprietary or financial interest in the products or companies described in this article. N.M. worked in collaboration on an Innovate UK (IUK) grant with Asymptote, which was quoted in the article as an example of a point of use thawing technology.

\section{References}

[1] Harrison RP, Rafiq QA, Medcalf N. Automating decentralized manufacturing of cell \& gene therapy products. Cell Gene Ther Insights 2016;2:115-20. doi:10.18609/cgti.2016.014.

[2] Mourtzis D, Doukas MM, Mourtzis D, Doukas MM. Decentralized manufacturing systems review: challenges and outlook. Logist Res 2012;5:113-21. doi:10.1007/s12159-0120085-x.

[3] Zylberberg C, Charo A, Haddock R, Lin-Gibson S, Lumelsky $\mathrm{N}$, Petersen T, et al. Manufacturing cell therapies: the paradigm shift in healthcare of this century. NAM Perspect 2017 ; in press.

[4] HM Government. Building our industrial strategy. HM Gov Green Pap 2017;https://www.gov.uk/government/uploads/ system/uploads/attachment_data/file/586626/building-our -industrial-strategy-green-paper.pdf.

[5] Pantelidou H, Casey G, Chapman T, Guthrie P, Soga K. Re-thinking UK transport emissions - getting to the 2050 targets. Proc Inst Civ Eng Civ Eng 2016;169:177-83. doi: $10.1680 /$ jcien.15.00076.

[6] Medcalf N. Centralized or decentralized manufacturing? Key business model considerations for cell therapies. Cell Gene Ther Insights 2016;2:95-109. doi:10.18609/cgti.2016.012.

[7] Jessop ZM, Al-Sabah A, Gardiner MD, Combellack E, Hawkins K, Whitaker IS. 3D bioprinting for reconstructive surgery: principles, applications and challenges. J Plast Reconstr Aesthetic Surg 2017;doi:10.1016/j.bjps.2017.06.001.

[8] Mestre AM, Oliveira MD, Barbosa-Póvoa AP. Locationallocation approaches for hospital network planning under uncertainty. Eur J Oper Res 2014;240:791-806. doi:10.1016/ j.ejor.2014.07.024.

[9] Kemp P. Regenerative Medicine looking backward 10 years further on. Futur Med 2016.

[10] Mason J, Culme-Seymour EJ, Bonfiglio GA, Reeve BC. Cell therapy companies make strong progress from October 2012 to March 2013 amid mixed stock market sentiment. Cell Stem Cell 2013;12:644-7. doi:10.1016/j.stem.2013.05.017.

[11] Branke J, Farid SS, Shah N. Industry 4.0: a vision for personalized medicine supply chains? Cell Gene Ther Insights 2016;2:263-70. doi:10.18609/cgti.2016.027.

[12] Slama D, Puhlmann F, Morrish J, Bhatnagar RM. Enterprise IoT: strategies and best practices for connected products and services. 2015.

[13] Harrison RP, Ruck S, Medcalf N, Rafiq QA. Decentralized manufacturing of cell and gene therapies, overcoming challenges and identifying opportunities. Cytotherapy 2017;19:1140-51.

[14] Rowley J, Abraham E, Campbell A, Brandwein H, Oh S. Meeting lot-size challenges of manufacturing adherent cells for therapy. Bioprocess Int 2012;10:16-22.

[15] MMIP. Advanced therapies manufacturing action plan. 2016.

[16] Cell and Gene Therapy Catapult. Fisher BioServices CryoHub to co-locate with manufacturing centre. Cell Gene Ther Catapult Press Release; 2017. Available from: https:// ct.catapult.org.uk/news-media/fisher-bioservices'-cryohub -co-locate-manufacturing-centre. [Accessed 5 August 2017].

[17] Fothergill S, Gore T. The implications for employment of the shift to high-value manufacturing. Foresight, Gov Off Sci 2013.

[18] Turok I, Edge N. The jobs gap in Britain's cities: employment loss and labour market consequences. Urban Stud 1999;37:1451-2. doi:10.1177/030913250102500332.

[19] Davis C, Hogarth T, Gambin L, Breuer Z, Garrett R. Sector Skills Insights: Advanced Manufacturing. 2012.

[20] Porter ME. Competitive advantage, agglomeration economies, and regional policy. Int Reg Sci Rev 1996;19:85-90. doi:10.1177/016001769601900208.

[21] Heathman TRJ, Nienow W, McCall MJ, Coopman K, Kara B, Hewitt CJ. The translation of cell-based therapies: clinical landscape and manufacturing challenges. Regen Med 2015;10:49-64.

[22] EYGM Limited. Worldwide capital and fixed assets guide 2016. Ernst Young Glob Ltd 2016;137-42.

[23] Cell and Gene Therapy Catapult. Cell and Gene Therapy Catapult Annual Review 2016. 2016.

[24] Kimetrica. Population Explorer; 2012. Available from: https:// www.populationexplorer.com/. [Accessed 27 July 2017].

[25] Oak Ridge National Laboratory. LandScan; 2012. Available from: http://web.ornl.gov/sci/landscan/ [Accessed 27 July 2017].

[26] Valuation Office Agency. Valuation Office Agency: nondomestic rating statistics - GOV.UK. Valuat Off Agency Non-Domestic Rat Stat; 2017. Available from: https:// www.gov.uk/government/collections/valuation-office-agency -non-domestic-rating-statistics. [Accessed 27 July 2017].

[27] Colliers INTERNATIONAL. Offices Rents Map | United Kingdom. Off Rents Map; 2016. Available from: http:// 
www.colliers.com/en-gb/uk/insights/offices-rents-map. [Accessed 27 July 2017].

[28] Korn S. How much rent, rates and service charge can I expect to pay for offices?; 2016. Available from: http://www .simonkorn.co.uk/how-much-rent-rates-and-service-charge -can-i-expect-to-pay-for-offices/. [Accessed 27 July 2017].

[29] Kapletia D. Redistributed Manufacturing in Healthcare Network (RiHN) Launch Event and Sandpit Workshops Forum Outputs; 2015.

[30] Wei Teng C, Foley L, O’Neill P, Hicks C. An analysis of supply chain strategies in the regenerative medicine industry-Implications for future development. Int J Prod Econ 2014;149:211-25. doi:10.1016/j.ijpe.2013.06.006.

[31] Atala A, Allickson JG. Translational regenerative medicine. 1st ed. New York: Elsevier; 2014.

[32] Rafiq QA, Brosnan KM, Coopman K, Nienow AW, Hewitt CJ. Culture of human mesenchymal stem cells on microcarriers in a 51 stirred-tank bioreactor. Biotechnol Lett 2013;35:1233-45. doi:10.1007/s10529-013-1211-9.

[33] De Sousa PA, Downie JM, Tye BJ, Bruce K, Dand P, Dhanjal $S$, et al. Development and production of good manufacturing practice grade human embryonic stem cell lines as source material for clinical application. Stem Cell Res 2016;17:37990. doi:10.1016/j.scr.2016.08.011.

[34] Nienow AW, Rafiq QA, Coopman K, Hewitt CJ. A potentially scalable method for the harvesting of hMSCs from microcarriers. Biochem Eng J 2014;85:79-88. doi:10.1016/ j.bej.2014.02.005.

[35] Eaker S, Abraham E, Allickson J, Brieva TA, Baksh D, Heathman TRJ, et al. Bioreactors for cell therapies: current status and future advances. Cytotherapy 2017;19:9-18. doi:10.1016/j.jcyt.2016.09.011.

[36] Department for Business Energy and Industrial Strategy. Science and Innovation Audits: Wave 1 Summary Reports 2016.

[37] Harrison RP, Ruck S, Rafiq QA, Medcalf N. Decentralised manufacturing of cell and gene therapy products: learning from other healthcare sectors. Biotechnol Adv 2017;1-17. in press.

[38] UK BioIndustry Association. Building something great: UK's Global Bioscience Cluster 2016; 2016.

[39] Department for Business Innovation \& Skills. Industrial Strategy: UK Sector Analysis; 2012. doi:25/10/2014.

[40] Mehrabi MG, Ulsoy AG, Koren Y. Reconfigurable manufacturing systems: key to future manufacturing. J Intell Manuf 2000;11:413-19.

[41] Kendrick BA, Dhokia V, Newman ST. Strategies to realize decentralized manufacture through hybrid manufacturing platforms. Robot Comput Integr Manuf 2017;43:68-78. doi:10.1016/j.rcim.2015.11.007.

[42] Bravery CA, Carmen J, Fong T, Oprea W, Hoogendoorn KH, Woda J, et al. Potency assay development for cellular therapy products: an $\mathrm{ISCT}^{\star}$ review of the requirements and experiences in the industry. Cytotherapy 2013;15:9-19. doi:10.1016/j.jcyt.2012.10.008.

[43] Rafiq QA, Twomey K, Kulik M, Leschke C, O'Dea J, Callens $\mathrm{S}$, et al. Developing an automated robotic factory for novel stem cell therapy production. Regen Med 2016;11:351-4. doi:10.2217/rme-2016-0040.

[44] Nordström KM, Närhi MO, Vepsäläinen APJ. Services for distribution of tissue engineering products and therapies. Int J Product Perform Manag 2008;58:11-28. doi:10.1108/ 17410400910921056.

[45] Nikolaev NI, Liu Y, Hussein H, Williams DJ. The sensitivity of human mesenchymal stem cells to vibration and cold storage conditions representative of cold transportation. Interface 2012;2503-15.

[46] Coopman K, Medcalf N. From production to patient: challenges and approaches for delivering cell therapies. Stem Cell Res Community, Stemb 2014;44:doi:10.3824/ stembook.1.97.1.1.

[47] Kantoff PW, Higano CS, Shore ND, Berger R, Small EJ, Penson DF, et al. Sipuleucel-T immunotherapy for castrationresistant prostate cancer. N Engl J Med 2010;363:411-22. doi:10.1056/NEJMoa1615664.

[48] European Medicines Agency. Guideline on real time release testing EMA/CHMP/QWP/811210/2009-Rev1. Comm Med Prod Hum Use 2012;44:1-10.

[49] Duflou JR, Sutherland JW, Dornfeld D, Herrmann C, Jeswiet J, Kara S, et al. Towards energy and resource efficient manufacturing: a processes and systems approach. CIRP Ann - Manuf Technol 2012;61:587-609. doi:10.1016/ j.cirp.2012.05.002.

[50] Halldórsson Á, Kovács G. The sustainable agenda and energy efficiency: logistics solutions and supply chains in times of climate change. Int J Phys Distrib Logist Manag 2010;40:5-13. doi:10.1108/09600031011018019.

[51] Porter ME, Lee TH. The Strategy That Will Fix Health Care; 2013. Available from: https://hbr.org/2013/10/the-strategy -that-will-fix-health-care. [Accessed 14 July 2017].

\section{Appendix: Supplementary material}

Supplementary data to this article can be found online at doi:10.1016/j.jcyt.2018.05.003. 